\title{
Capital interplays and the self-rated health of young men: results from a cross-sectional study in Switzerland
}

\author{
Gerry Veenstra ${ }^{1 *}$ and Thomas Abel ${ }^{2}$
}

\begin{abstract}
Introduction: We apply capital interplay theory to health inequalities in Switzerland by investigating the interconnected effects of parental cultural, economic and social capitals and personal educational stream on the self-rated health of young Swiss men who live with their parents.

Methods: We apply logistic regression modelling to self-rated health in original cross-sectional survey data collected during mandatory conscription of Swiss male citizens in 2010 and $2011(n=23,975)$.

Results: In comparison with sons whose parents completed mandatory schooling only, sons with parents who completed technical college or university were significantly more likely to report very good or excellent self-rated health. Parental economic capital was an important mediating factor in this regard. Number of books in the home (parental cultural capital), family economic circumstances (parental economic capital) and parental ties to influential people (parental social capital) were also independently associated with the self-rated health of the sons. Although sons in the highest educational stream tended to report better health than those in the lowest, we found little evidence for a health-producing intergenerational transmission of capitals via the education stream of the sons. Finally, the positive association between personal education and self-rated health was stronger among sons with relatively poorly educated parents and stronger among sons with parents who were relatively low in social capital.
\end{abstract}

Conclusions: Our study provides empirical support for the role of capital interplays, social processes in which capitals interpenetrate or co-constitute one another, in the intergenerational production of the health of young men in Switzerland.

Keywords: Switzerland, Self-rated health, Education, Capitals, Capital interplays

\section{Introduction}

We investigate whether and how the cultural, economic and social capitals of Swiss parents and the educational stream of their sons influence the self-rated health of the sons. Inspired by the theories of Pierre Bourdieu [1-4], we use the term 'capital' to refer to resources for individual action that are socially valued and objects of struggle. For Bourdieu, the most centrally important forms of capital in social life are cultural capital, economic capital and social capital. Cultural capital refers to material and non-material resources that originate in prevailing social

\footnotetext{
* Correspondence: gerry.veenstra@ubc.ca

'Department of Sociology, University of British Columbia, 6303 N. W. Marine Drive, Vancouver, BC V6T 1Z1, Canada

Full list of author information is available at the end of the article
}

systems of values and symbols. An educational credential is an institutionalized form of cultural capital that represents a certificate of cultural competence which confers on its holder a conventional, constant and legally guaranteed value with respect to culture. Cultural tastes and inclinations, lasting dispositions of mind and body that are socially desirable and relatively rare, represent an embodied form of cultural capital. Objectified cultural capital refers to the possession of valued cultural goods such as books, works of art and machines that require specialized cultural abilities to use. The second primary form of capital, economic capital, refers to money and other assets such as property that can be directly converted into money. The third primary form of capital, social capital, refers to resources embedded in relationships 
of mutual acquaintance or recognition. Access to the capitals held by others effectively serves to augment or enhance an individual's own stock of cultural and economic capitals.

Previous research indicates that each of these three distinct forms of capital is implicated in health inequalities. For example, the health effects of institutionalized cultural capital and economic capital have been extensively investigated under the rubric of socioeconomic status and health [5-8]. Embodied cultural capital has also received some attention in recent years [9-13] and research on social capital and health is now voluminous [14-16]. For the most part, these studies have documented distinct health effects of the various forms of capital, typically finding that, all else being equal, more capital tends to correspond with better health.

Rather than treating the various capitals as conceptually and empirically distinct determinants of health, we contend that these capitals are regularly interwoven with one another in processes that produce good health. In this regard our study is influenced by Bourdieu's ideas pertaining to capital conversions as well as recent discussions on the health effects of what are variously called capital interplays, interactions, relations or transformations [17-20]. Put simply, capital interplays refer to social processes wherein capitals interpenetrate or coconstitute one another. We hypothesize that three kinds of capital interplay are potentially pertinent for the generation of good health, namely, capital acquisition interplays, capital transmission interplays and capital multiplier interplays. We examine each of these intergenerational processes as a generator of positive self-rated health in a sample of young Swiss men collected in 2010-2011 during the process of mandatory conscription of eligible male citizens.

\section{Capital acquisition interplays}

Capital acquisition interplays refer to processes whereby one form of capital facilitates the successful acquisition of another form of capital and then good health. Capital acquisition interplays includes processes wherein parental institutionalized cultural capital facilitates acquisition of other forms of parental capital which subsequently influence the health of the children [21]. After establishing a statistical relationship between the educational credentials of parents and the self-rated health of their sons, we use indicators of various cultural, economic and social capitals held by the parents to explicate the health effects of parental education.

Specifically, inspired by previous research that indicates that the number of books in the home is a valid and reliable indicator of cultural capital [22,23], we use number of books in the home to assess the objectified cultural capital possessed by the families in our study. In this regard we hypothesize that higher educated parents are likely to have a relatively large number of books and that these books add to or reflect the stock of cultural capital in the family. If parental institutionalized cultural capital is a guarantor of command of highbrow culture, then possessing books (objectified cultural capital) is a physical representation of familiarity and facility with social practices typical of highbrow (valued and valuable) culture. We hypothesize that this stock of cultural capital subsequently facilitates the health of their sons via associated social practices, such as parents regularly reading aloud to children when they are young or enrolling children in healthful extracurricular activities (e.g., certain kinds of organized sporting activities). In short, number of books in the family, facilitated by parental education, is an indicator of parental cultural resources broadly writ that function to promote the health of their sons.

We use a measure of perceived financial circumstances to assess parental economic capital. We hypothesize that parental education is strongly related to parental economic capital due to the strong links in Swiss society between educational credentials and occupations. We also hypothesize that economic capital in families is associated with the health of the sons for reasons that relate to the material components of health-related social practices, such as healthy dietary practices in the home (e.g., good food is expensive), and to the accessibility of status symbols (e.g., cars, clothes, practices, etc.) that can foster a sense of security and material stability.

We use perceived parental connections to influential people to assess the social capital of the parents. We hypothesize that higher educated parents will tend to have social ties to highly educated others due to the principle of homophily (birds of a feather flock together) and, therefore, will possess relatively influential ties. We also hypothesize that sons who know that they can rely on their parents' social capital when needed and who are regularly reassured of their own high social status because of the presence of these potent social ties will be relatively likely to report high levels of health as a consequence.

\section{Capital transmission interplays}

Capital transmission interplays refer to processes whereby one person's portfolio of capitals is used to contribute to or reshape another person's portfolio of capitals and, accordingly, their health. This includes processes whereby parental capital indirectly influences children's health via the educational stream of the children [24]. We investigate whether the health effects of parental capitals are explained by the institutionalized cultural capital of the sons by way of four distinct capital transmission interplays. 
First, we hypothesize that the sons of parents with higher educational degrees are relatively likely to be in higher education streams, in part because highly educated parents tend to transmit to and inculcate in their children norms and values that lead their children to (seek to) achieve higher educational credentials themselves. Second, we hypothesize that parents with many books in the home are relatively likely to have sons in higher education streams. Here we posit that number of books in the home is an indicator of a broad range of cultural resources representing linguistic abilities more generally that provides sons with valuable skills for succeeding in the educational system. Third, we hypothesize that parents with more economic capital are more likely to have sons in higher education streams. Wealthier families use higher-level schooling for their children as a strategy for transmitting economic capital to their children via means other than inheritance. In addition, in the Swiss education system a large number of children in the higher streams receive extra-curricular teaching requiring economic investment on the part of the parents. Finally, we hypothesize that parents with more social capital are more likely to have sons in higher education streams. Parental interventions in school can help children succeed in the school system and parents often use their social capital for these kinds of interventions. In addition, parents can use their social capital to select schools that will maximize their children's chances of succeeding scholastically.

\section{Capital multiplier interplays}

Capital multiplier interplays refer to processes whereby the successful application of one form of capital is facilitated by possession of another form of capital, that is, where one form of capital multiplies the effect of another. Multiplier interplays include scenarios wherein the health effect of the educational stream of the sons is facilitated or strengthened by capitals held by the parents. First we examine whether the health effect of the educational stream of the sons is conditional upon the education level of the parents, hypothesizing that personal education will be more strongly associated with self-rated health among sons with higher educated parents than among sons with lower educated parents. This could occur because some of the health promoting characteristics of grammar school environments, such the presence of gymnasiums for certain kinds of physical activity, are more efficacious for the health for sons who are already familiar with the activities that occur in them from early childhood experiences with like-educated parents. In addition, sons may be able to apply their own educational capital more effectively in the labour market and elsewhere when the process of doing so has been previously modelled for them by their parents. Second, we examine whether the health effect of the educational stream of the sons is conditional upon the number of books in the home, hypothesizing that personal education will be more strongly associated with self-rated health among sons with parents who are relatively rich in this form of cultural capital. In this regard the presence of books in the home functions as an indicator of prior familiarity with the intellectual content of higher educational stream settings. Third, we determine whether the health effect of educational stream is conditional upon the economic capital held by the parents, hypothesizing that personal education will be more strongly associated with self-rated health among sons with parents who are relatively wealthy. This could occur if personal education is less efficacious for the production of the good health of people who lack the financial background to implement the healthy lifestyle choices common in the social circles inhabited by people of similar educational attainment. Finally, we hypothesize that the health effect of educational stream is more strongly associated with self-rated health among sons from families with relatively more social capital. Social capital is an indicator of familiarity with values and norms prevalent in higher track education settings that in turn could facilitate more efficacious use of the health promoting aspects of higher educational stream settings.

\section{Methods}

\section{Survey sample}

Our study uses data from the Young Adults Swiss Survey (YASS). The YASS was ethically approved by the supervising board of nine members representing the Swiss National Science Foundation and the Federal Statistical Office. Study procedures were also ethically approved by the scientific advisory board of the YASS study. The target population consisted of all Swiss male citizens of conscription age (around nineteen years of age). Data collection was conducted in 2010 and 2011 at the six national recruiting centres in Switzerland where recruitment for compulsory military service occurs. Participation in the cross-sectional survey was voluntary and anonymous. In total, 31,424 young Swiss men, approximately $40 \%$ of the entire population of Swiss men in this cohort, participated in the YASS study. The survey was administered as a paper-and-pencil questionnaire in a classroom setting and was available in German, French and Italian. The survey was administered by non-military staff and collection and processing methods were not linked to the actual conscription procedure. We restricted our investigation to those survey respondents $(n=28,795)$ who lived with one or both parents at the time of the survey. We further restricted our analyses to those respondents $(n=23,975)$ who provided information for all of the variables used in our study. Table 1 describes socio- 
Table 1 Characteristics of the sample

\begin{tabular}{|c|c|c|c|}
\hline Variable & Categories & $\mathrm{n}$ & $\%$ \\
\hline \multirow[t]{9}{*}{ Age } & 17 years & 7 & 0.0 \\
\hline & 18 years & 6,424 & 26.8 \\
\hline & 19 years & 10,850 & 45.3 \\
\hline & 20 years & 4,790 & 20.0 \\
\hline & 21 years & 1,323 & 5.5 \\
\hline & 22 years & 386 & 1.6 \\
\hline & 23 years & 110 & 0.5 \\
\hline & 24 years & 68 & 0.3 \\
\hline & 25 years & 17 & 0.1 \\
\hline \multirow[t]{2}{*}{ Immigrant status } & born in Switzerland & 22,426 & 93.5 \\
\hline & immigrated to Switzerland & 1,549 & 6.5 \\
\hline \multirow[t]{6}{*}{ Recruitment centre } & Lausanne & 4,187 & 17.5 \\
\hline & Sumiswald & 3,080 & 12.9 \\
\hline & MtCeneri & 1,437 & 6.0 \\
\hline & Windisch & 7,422 & 31.0 \\
\hline & Ruti & 4,281 & 17.9 \\
\hline & Mels & 3,568 & 14.9 \\
\hline \multirow[t]{5}{*}{ Highest parental education } & mandatory schooling & 579 & 2.4 \\
\hline & vocational & 10,588 & 44.2 \\
\hline & grammar school & 1,182 & 4.9 \\
\hline & technical college & 5,171 & 21.6 \\
\hline & university & 6,455 & 26.9 \\
\hline \multirow[t]{3}{*}{ Personal educational stream } & mandatory schooling & 1,496 & 6.2 \\
\hline & vocational & 13,824 & 57.7 \\
\hline & grammar school & 8,655 & 36.1 \\
\hline \multirow[t]{5}{*}{ Number of books in the home } & 0 to 10 & 2,026 & 8.5 \\
\hline & 11 to 50 & 6,864 & 28.6 \\
\hline & 51 to 200 & 7,426 & 31.0 \\
\hline & 201 to 400 & 3,934 & 16.4 \\
\hline & more than 400 & 3,725 & 15.5 \\
\hline \multirow[t]{4}{*}{ Parental financial condition } & very bad & 614 & 2.6 \\
\hline & bad & 4,287 & 17.9 \\
\hline & good & 14,305 & 59.7 \\
\hline & very good & 4,769 & 19.9 \\
\hline \multirow[t]{4}{*}{ Parental social capital } & very unlikely & 1,171 & 4.9 \\
\hline & rather unlikely & 3,144 & 13.1 \\
\hline & rather likely & 7,154 & 29.8 \\
\hline & very likely & 12,506 & 52.2 \\
\hline \multirow[t]{5}{*}{ Self-rated health } & poor & 63 & 0.3 \\
\hline & fair & 710 & 3.0 \\
\hline & good & 7,483 & 31.2 \\
\hline & very good & 10,949 & 45.7 \\
\hline & excellent & 4,770 & 19.9 \\
\hline
\end{tabular}

demographic characteristics of the final sample of survey respondents.

\section{Survey measures}

In Switzerland, approximately one third of adolescents attend grammar schools that lead to university entrance diplomas and then, typically, technical college or university. About six in ten do vocational training in manual or office jobs with one day of vocational school per week. Our respondents were asked about their mother and father's levels of educational attainment, enabling us to calculate highest parental education attainment. In this regard we distinguish between five levels of parental education: mandatory schooling only, vocational training, grammar school, technical college and university. We use educational stream in three categories to assess the institutionalized cultural capital of the sons, distinguishing between mandatory schooling only, vocational training and grammar school.

To assess the objectified cultural capital of the parents, respondents were asked "How many books are there in your parents' home?" with response categories 'none or only a few (0-10), 'enough to fill a book shelf (11-50),' 'enough to fill a book case (51-200),' 'enough to fill two book cases (201-400)' and 'enough to fill three or more book cases (more than 400).' To assess perceived economic capital, respondents were asked "How financially well-off are your parents?" with response categories 'very good financial conditions,' 'good financial conditions,' 'modest financial conditions' and 'very modest financial conditions.' The social capital of parents was assessed by asking respondents "Should you need support from someone in an influential position, someone with connections, could your parents arrange such a contact?" with response categories 'very likely', 'rather likely', 'rather unlikely' and 'very unlikely.' Consistent with Bourdieu's understanding of social capital, this measure of social capital, unlike most others in the health determinants literature, focuses on access to the capitals held by others rather than on the presence or number of social ties of any and all kinds.

Global self-rated health, known to encompass both physical and mental well-being and to reliably predict other, more objective, measures of health [25] as well as mortality [26], was assessed as follows: "How would you rate your health status in general?" with response categories 'excellent,' 'very good,' 'good, 'fair' and 'poor.'

\section{Statistical methods}

Binary logistic regression modelling was applied to selfrated health which we coded poor, fair or $\operatorname{good}=0$ and very good or excellent $=1$. We introduced two-way multiplicative terms to regression models in order to examine statistical interactions between capital variables 
as predictors of very good or excellent health. Likelihood ratio tests were applied post hoc to assess the statistical significance of the interactions.

\section{Results}

A series of six main effects models on self-rated health are presented in Table 2. Model 1 describes the relationship between parental education and the self-rated health of the sons, controlling for the age and immigrant status of the sons only. In comparison with sons with parents who completed mandatory schooling only, sons with parents who completed grammar school $(\mathrm{OR}=$ 1.230, 95\% CI $=1.005-1.513)$, technical college $(\mathrm{OR}=$ $1.342,95 \% \mathrm{CI}=1.123-1.604)$ or university $(\mathrm{OR}=1.354$, $95 \% \mathrm{CI}=1.136-1.614)$ were significantly more likely to report better self-rated health scores.

\section{Capital acquisition interplays}

Models 2 through 4 in Table 2 address the degree to which number of books in the home, family economic circumstances and the social capital of parents, respectively, explain the association between parental education and the self-rated health of the sons. These models indicate that, although all three factors are relevant in this regard, economic capital is the more important potentially mediating factor. As a set the three parental capitals explain all of the variability in the self-rated health of the sons attributable to parental education (Model 5).

\section{Capital transmission interplays}

Model 6 in Table 2 indicates that, controlling for the parental capitals, sons in the vocational $(\mathrm{OR}=1.448$, $95 \% \mathrm{CI}=1.296-1.617)$ or grammar school $(\mathrm{OR}=1.580$, $95 \% \mathrm{CI}=1.405-1.776)$ streams were significantly more likely than sons with only mandatory schooling to report better self-rated health. Number of books in the home, perceived financial condition of the family and parental ties with influential others also manifest significant and positive associations with health in this model. Substantially unchanged coefficients for parental capitals from Model 5 to Model 6 indicate that none of the associations between parental capitals and the self-rated health of the sons is explained by the educational stream of the sons. That is, we find little evidence that the transmission of capitals of parents to the institutionalized cultural capital of sons explains variability in the self-rated health of the sons.

\section{Capital multiplier interplays}

Interaction models depicting possible capital multiplier interplays are described in Table 3. For these analyses we dichotomized parental education (university or not), books in the home (more than fifty or fewer than fifty), parental financial condition (very good or not) and parental social capital (very likely or not). Model 1 in Table 3 describes the main effects of the various capital variables on self-rated health while Model 2 describes the interaction between parental education and the educational stream of the sons (the LR test comparing Models 1 and 2 produced $p=0.03$ ). Contrary to expectations, personal education was more strongly associated with self-rated health among young men whose parents had less schooling. Among respondents whose parents had not completed university, the odds of sons reporting very good or excellent health were $1.686(95 \% \mathrm{CI}=$ 1.469-1.936) times as high for sons in the vocational stream as they were for sons in the mandatory schooling stream and $1.850(95 \% \mathrm{CI}=1.590-2.153)$ times as high for sons in the grammar stream as they were for sons in the mandatory schooling stream. Reproducing Model 2 with parental education reverse coded (model not shown) indicates that the same odds ratios were smaller among respondents whose parents completed university $(\mathrm{OR}=1.262,95 \% \mathrm{CI}=1.051-1.515$ and $\mathrm{OR}=1.354,95 \%$ $\mathrm{CI}=1.127-1.627$, respectively). The interactions between books in the home and educational stream (Model 3) and parental economic capital and educational stream (Model 4$)$ were not statistically significant $(p>0.05$ in both cases). Model 5 describes the interaction between parental social capital and the educational stream of the sons $(p=0.02)$. Among respondents whose parents had not completed university, the odds of sons reporting very good or excellent health were 1.590 (95\% CI = 1.344-1.879) times as high for sons in the vocational stream as they were for sons in the mandatory schooling stream and $1.837(95 \% \mathrm{CI}=1.547-2.183)$ times as high for sons in the grammar stream as they were for sons in the mandatory schooling stream. Reproducing Model 5 with parental social capital reverse coded (model not shown) indicates that these odds ratios were smaller among respondents whose parents completed university $(\mathrm{OR}=1.471,95 \% \mathrm{CI}=1.271-1.702$ and $\mathrm{OR}=1.462,95 \%$ $\mathrm{CI}=1.252-1.708$, respectively).

\section{Conclusions}

Limitations of the study include the fact that each form of capital was assessed by a single indicator. In addition, the measure of cultural capital, assessing number of books in the home, did not account for the kinds of books owned by parents, presumably not all of which can be deemed elements of cultural capital. The measures were based on self-reports, potentially introducing unknown bias in our assessments of individual resources, and the data was cross-sectional, limiting our ability to make definitive causal interpretations. In addition, the study was restricted to a single cohort of young Swiss men, limiting the temporal applicability of our findings. Finally, to the degree that injured or sick men postpone 
Table 2 Binary logistic regression main effect models on excellent/very good self-rated health

\begin{tabular}{|c|c|c|c|c|c|c|c|c|c|c|c|c|c|}
\hline & & $\begin{array}{l}\text { Model } \\
1\end{array}$ & & $\begin{array}{l}\text { Model } \\
2\end{array}$ & & $\begin{array}{l}\text { Model } \\
3\end{array}$ & & $\begin{array}{l}\text { Model } \\
4\end{array}$ & & $\begin{array}{l}\text { Model } \\
5\end{array}$ & & $\begin{array}{l}\text { Model } \\
6\end{array}$ & \\
\hline Variable & Categories & OR & $95 \% \mathrm{Cl}$ & OR & $95 \% \mathrm{Cl}$ & OR & $95 \% \mathrm{Cl}$ & OR & $95 \% \mathrm{Cl}$ & OR & $95 \% \mathrm{Cl}$ & OR & $95 \% \mathrm{Cl}$ \\
\hline \multirow[t]{5}{*}{ Highest parental education } & $\begin{array}{l}\text { mandatory schooling } \\
\text { (reference) }\end{array}$ & 1.000 & & 1.000 & & 1.000 & & 1.000 & & 1.000 & & 1.000 & \\
\hline & vocational & 1.130 & $0.951 . .1 .344$ & 1.061 & $0.892 . .1 .264$ & 1.005 & $0.843 . .1 .197$ & 1.068 & $0.897 . .1 .271$ & 0.929 & $0.778 . .1 .110$ & 0.911 & $0.762 . .1 .988$ \\
\hline & grammar school & $1.230^{*}$ & $1.005 . .1 .513$ & 1.101 & $0.892 . .1 .358$ & 1.060 & $0.860 . .1 .307$ & 1.157 & $0.939 . .1 .425$ & 0.944 & $0.762 . .1 .168$ & 0.912 & 0.736 .1 .129 \\
\hline & technical college & $1.342^{* *}$ & $1.123 . .1 .604$ & $1.219^{*}$ & 1.017..1.460 & 1.107 & $0.923 . .1 .327$ & $1.217^{*}$ & $1.016 . .1 .456$ & 0.977 & $0.812 . .1 .175$ & 0.946 & $0.786 . .1 .139$ \\
\hline & university & $1.354^{* *}$ & $1.136 . .1 .614$ & 1.180 & $0.984 . .1 .415$ & 1.047 & $0.875 . .1 .253$ & $1.224^{*}$ & 1.025..1.462 & 0.904 & $0.750 . .1 .088$ & 0.861 & $0.714 . .1 .038$ \\
\hline \multirow[t]{5}{*}{ Number of books in the home } & 0 to 10 (reference) & & & 1.000 & & & & & & 1.000 & & 1.000 & \\
\hline & 11 to 50 & & & $1.195^{* *}$ & 1.078..1.324 & & & & & $1.175^{* *}$ & 1.058..1.304 & $1.159^{* *}$ & 1.044..1.287 \\
\hline & 51 to 200 & & & $1.309^{* * *}$ & $1.180 . .1 .452$ & & & & & $1.291^{* * *}$ & $1.162 . .1 .435$ & $1.255^{* * *}$ & 1.129..1.395 \\
\hline & 201 to 400 & & & $1.397^{* * *}$ & $1.244 . .1 .570$ & & & & & $1.343^{* * *}$ & 1.194..1.512 & $1.290^{* * *}$ & $1.145 . .1 .454$ \\
\hline & more than 400 & & & $1.365^{* * *}$ & $1.209 . .1 .539$ & & & & & $1.287^{* * *}$ & $1.139 . .1 .455$ & $1.227^{* *}$ & 1.083..1.390 \\
\hline \multirow[t]{4}{*}{ Parental financial condition } & very bad (reference) & & & & & 1.000 & & & & 1.000 & & 1.000 & \\
\hline & bad & & & & & $1.262^{* *}$ & 1.064..1.497 & & & $1.214^{*}$ & $1.022 . .1 .441$ & $1.199^{*}$ & 1.009..1.424 \\
\hline & good & & & & & $1.860^{* * *}$ & 1.579..2.192 & & & $1.701^{* * *}$ & $1.440 . .2 .009$ & $1.656^{* * *}$ & $1.402 . .1 .958$ \\
\hline & very good & & & & & $3.073^{* * *}$ & $2.582 . .3 .659$ & & & $2.656^{* * *}$ & $2.223 . .3 .172$ & $2.600^{* * *}$ & 2.176..3.107 \\
\hline \multirow[t]{4}{*}{ Parental social capital } & very unlikely (reference) & & & & & & & 1.000 & & 1.000 & & 1.000 & \\
\hline & rather unlikely & & & & & & & $1.259^{* *}$ & 1.099..1.443 & $1.153^{*}$ & $1.004 . .1 .323$ & 1.142 & $0.995 . .1 .312$ \\
\hline & rather likely & & & & & & & $1.425^{* * *}$ & $1.257 . .1 .617$ & $1.241^{* *}$ & $1.091 . .1 .411$ & $1.239^{* *}$ & 1.089..1.410 \\
\hline & very likely & & & & & & & $1.881^{* * *}$ & $1.664 . .2 .126$ & $1.499 * * *$ & 1.322..1.701 & $1.524^{* * *}$ & 1.342..1.729 \\
\hline \multirow[t]{3}{*}{ Educational stream } & $\begin{array}{l}\text { mandatory schooling } \\
\text { (reference) }\end{array}$ & & & & & & & & & & & 1.000 & \\
\hline & vocational & & & & & & & & & & & $1.448^{* * *}$ & $1.448^{* * *}$ \\
\hline & grammar school & & & & & & & & & & & $1.580^{* * *}$ & $1.405 . .1 .776$ \\
\hline \multicolumn{2}{|l|}{ Chi-square (p) } & \multicolumn{2}{|c|}{$219.82(<0.001)$} & \multicolumn{2}{|c|}{$259.56(<0.001)$} & \multicolumn{2}{|c|}{$643.93(<0.001)$} & \multicolumn{2}{|c|}{$412.65(<0.001)$} & \multicolumn{2}{|c|}{$751.16(<0.001)$} & \multicolumn{2}{|c|}{$808.88(<0.001)$} \\
\hline
\end{tabular}


Table 3 Binary logistic regression interaction models on excellent/very good self-rated health

\begin{tabular}{|c|c|c|c|c|c|c|c|c|c|c|c|}
\hline & & $\begin{array}{l}\text { Model } \\
1\end{array}$ & & $\begin{array}{l}\text { Model } \\
2\end{array}$ & & $\begin{array}{l}\text { Model } \\
3\end{array}$ & & $\begin{array}{l}\text { Model } \\
4\end{array}$ & & $\begin{array}{l}\text { Model } \\
5\end{array}$ & \\
\hline Variable & Categories & OR & $95 \% \mathrm{Cl}$ & OR & $95 \% \mathrm{Cl}$ & OR & $95 \% \mathrm{Cl}$ & OR & $95 \% \mathrm{Cl}$ & OR & $95 \% \mathrm{Cl}$ \\
\hline \multirow[t]{2}{*}{ Highest parental education } & less than university (reference) & 1.000 & & 1.000 & & 1.000 & & 1.000 & & 1.000 & \\
\hline & university & 1.027 & $0.970 . .1 .089$ & $1.357^{* *}$ & 1.092..1.686 & 1.026 & 0.968..1.087 & 1.027 & $0.970 . .1 .089$ & 1.029 & $0.971 . .1 .091$ \\
\hline \multirow[t]{2}{*}{ Number of books in the home } & 50 or fewer (reference) & 1.000 & & 1.000 & & 1.000 & & 1.000 & & 1.000 & \\
\hline & more than 50 & $1.124^{* * *}$ & 1.059..1.193 & $1.124^{* * *}$ & 1.059..1.193 & 1.018 & $0.827 . .1 .252$ & $1.125^{* * *}$ & $1.060 . .1 .194$ & $1.125^{* * *}$ & 1.059..1.194 \\
\hline \multirow[t]{2}{*}{ Parental financial condition } & less than very good (reference) & 1.000 & & 1.000 & & 1.000 & & 1.000 & & 1.000 & \\
\hline & very good & $1.684^{* * *}$ & 1.562..1.817 & $1.687^{* * *}$ & 1.564..1.820 & $1.682^{* * *}$ & 1.559..1.814 & $2.023^{* * *}$ & 1.527..2.681 & $1.688^{* * *}$ & 1.565 .1 .820 \\
\hline \multirow[t]{2}{*}{ Parental social capital } & less than very likely (reference) & 1.000 & & 1.000 & & 1.000 & & 1.000 & & 1.000 & \\
\hline & very likely & $1.324^{* * *}$ & $1.252 . .1 .400$ & $1.325^{* * *}$ & 1.253..1.401 & $1.323^{* * *}$ & $1.251 . .1 .399$ & $1.323^{* * *}$ & $1.252 . .1 .400$ & $1.500^{* * *}$ & 1.214..1.851 \\
\hline \multirow[t]{3}{*}{ Educational stream } & mandatory schooling (reference) & 1.000 & & 1.000 & & 1.000 & & 1.000 & & 1.000 & \\
\hline & vocational & $1.516^{* * *}$ & 1.385..1.692 & $1.686^{* * *}$ & 1.469..1.936 & $1.458^{* * *}$ & 1.249..1.703 & $1.578^{* * *}$ & $1.399 . .1 .780$ & $1.590^{* * *}$ & 1.344..1.879 \\
\hline & grammar school & $1.636^{* * *}$ & 1.457..1.836 & $1.850^{* * *}$ & 1.590..2.153 & $1.457^{* * *}$ & $1.220 . .1 .740$ & $1.671^{* * *}$ & $1.472 . .1 .896$ & $1.837^{* * *}$ & 1.547..2.181 \\
\hline \multirow{4}{*}{$\begin{array}{l}\text { Highest parental education*educational } \\
\text { stream }\end{array}$} & less than university and vocational (reference) & & & 1.000 & & & & & & & \\
\hline & university and vocational & & & $0.748^{*}$ & $0.595 . .0 .940$ & & & & & & \\
\hline & less than university and grammar (reference) & & & 1.000 & & & & & & & \\
\hline & university and grammar & & & $0.732^{*}$ & $0.578 . .0 .927$ & & & & & & \\
\hline \multirow{4}{*}{$\begin{array}{l}\text { Number of } \\
\text { books*educational stream }\end{array}$} & 50 or fewer and vocational (reference) & & & & & 1.000 & & & & & \\
\hline & more than 50 and vocational & & & & & 1.083 & $0.870 . .1 .347$ & & & & \\
\hline & 50 or fewer and grammar (reference) & & & & & 1.000 & & & & & \\
\hline & more than 50 and grammar & & & & & 1.202 & $0.949 . .1 .522$ & & & & \\
\hline \multirow{5}{*}{$\begin{array}{l}\text { Parental financial } \\
\text { condition*educational stream }\end{array}$} & less than very good and vocational (reference) & & & & & & & 1.000 & & & \\
\hline & very good and vocational & & & & & & & 0.787 & $0.584 . .1 .059$ & & \\
\hline & $\begin{array}{l}\text { less than very good and grammar } \\
\text { (reference) }\end{array}$ & & & & & & & 1.000 & & & \\
\hline & very good and grammar & & & & & & & 0.880 & $0.647 . .1 .196$ & & \\
\hline & & & & & & & & & & 1.000 & \\
\hline
\end{tabular}


Table 3 Binary logistic regression interaction models on excellent/very good self-rated health (Continued)

\begin{tabular}{|c|c|c|c|c|c|c|c|}
\hline \multirow[t]{4}{*}{$\begin{array}{l}\text { Parental social capital*educational } \\
\text { stream }\end{array}$} & $\begin{array}{l}\text { less than very likely and vocational } \\
\text { (reference) }\end{array}$ & & & & & & \\
\hline & very likely and vocational & & & & & 0.925 & $0.741 . .1 .155 \mid$ \\
\hline & less than very likely and grammar (reference) & & & & & 1.000 & \\
\hline & very likely and grammar & & & & & 0.796 & $0.632 . .1 .001$ \\
\hline Chi-square (p) & & $665.72(p<0.001)$ & $672.70(p<0.001)$ & $669.05(p<0.001)$ & $669.48(p<0.001)$ & 673.65 & $<0.001)$ \\
\hline
\end{tabular}


their visits to the conscription centres the prevalence of poor health is underrepresented by our sample. Nonetheless our findings speak to the potentially important role played by the educational system in the intergenerational production and reproduction of social and health inequalities in Switzerland and the relevance of capital interplays for illuminating processes by which this occurs. In particular, our study indicates that capital interplays are central to the successful application of parental institutionalized cultural capital towards achieving the good health of male children in Switzerland.

Consistent with previous research [21,24,27-30], we found that, in comparison with sons whose parents completed mandatory schooling only, sons with parents who completed technical college or university were significantly more likely to report better self-rated health. This result calls for further illumination of the mechanisms by which good health is facilitated by intergenerational social processes. To this end we found that parental economic capital was a potentially important mediating factor in the presumed effect of parental education on the health of their sons, suggesting that material circumstances in childhood are factors in the production of good health among young Swiss men. We also found that number of books in the home manifested an independent association with the health of the young men, suggesting that incorporating book-reading into childrearing practices and fostering familiarity with cultural symbols of high social status in childhood may be health-relevant forms of embodied cultural capital. Parental social ties to influential people also manifested an independent association with the health and wellbeing of these young men, suggesting that familial access to the capitals of others may be additional resources for the production of good health. Finally, we found that the positive association between educational stream and self-rated health was stronger among young men with lesser educated parents and stronger among young men with parents who were relatively low in social capital. Incompatible with multiplier interplays as we have depicted them here, these results suggest that the health gains stemming from higher-level school environments and/or higher-level educational credentials may partly compensate for the social disadvantage that accompanies lower levels of cultural and social capitals in families.

In conclusion, we find empirical support for all of the capital acquisition interplays examined in our study, namely, that parental institutionalized cultural capital facilitates the acquisition of parental objectified cultural capital (books in the home), parental economic capital (wealth) and parental social capital (ties to influential people) that then foster the health of young men in Switzerland. We do not find empirical support for any of the capital transmission interplays examined in our study, namely, that parental capitals shape the educational stream of the young men and thence their health. Rather, we find that these diverse parental and personal capitals manifest independent associations with the selfrated health of these men. Finally, we find no support for the multiplier interplays examined here, namely, that the positive effects of educational stream are stronger for sons with parents possessing more capital of various kinds. Instead, we find that the positive effects of educational stream are stronger for sons whose parents are low in institutionalized cultural capital or low in social capital. We proffer the latter interplays as instances of another kind of capital interplay that can affect health, what we call compensatory capital interplays. Future health research in this and other contexts should examine the applicability of this capital interplay as well as the acquisition, transmission and multiplier capital interplays outlined above.

\section{Competing interests}

The authors declare that they have no competing interests.

\section{Authors' contributions}

GV and TA originally conceived of the study, TA obtained the survey data, GV analyzed the data and GV and TA drafted the manuscript. Both authors read and approved the final manuscript.

\section{Acknowledgements}

Project management for the YASS study was provided by the Institute for the Management and Economics of Education, University of Teacher

Education Central Switzerland Zug (contact: Stephan Huber). The research partners included the Institute for Education Evaluation, University of Zurich (contact: Urs Moser); the Institute of Social and Preventive Medicine, University of Bern (contact: Thomas Abel); and the Department of Sociology, University of Geneva (contact: Sandro Cattacin). Gerry Veenstra was supported by a Killam Faculty Research Fellowship (2013) awarded by the University of British Columbia during the time of this research. Warm thanks are extended to the Institute of Social and Preventive Medicine at the University of Bern for hosting GV's sabbatical visit in 2013

\section{Author details}

${ }^{1}$ Department of Sociology, University of British Columbia, 6303 N. W. Marine Drive, Vancouver, BC V6T 1Z1, Canada. ${ }^{2}$ Institute of Social and Preventive Medicine, University of Bern, Bern, Switzerland.

Received: 5 November 2014 Accepted: 10 April 2015

Published online: 18 April 2015

\section{References}

1. Bourdieu P, Passeron J. Reproduction in education, society and culture. 2nd ed. London: Sage Publications; 1990 [1970].

2. Bourdieu P. Distinction. A social critique of the judgment of taste. Cambridge: Harvard University Press; 1984 [1978].

3. Bourdieu P. The forms of capital. In: Richardson J, editor. Handbook of theory and research for the sociology of education. New York: Greenwood Press; 1986. p. 241-58 [1983].

4. Bourdieu P. Practical reason. On the theory of action. Stanford: Stanford University Press; 1998 [1994].

5. Braveman P, Cubbin C, Egerter S, Williams DR, Pamuk E. Socio-economic disparities in health in the United States: what the patterns tell us. Am J Public Health. 2010;100:186-96.

6. Braveman $P$, Egerter $S$, Williams D. The social determinants of health: coming of age. Annu Rev Public Health. 2011;32:381-98.

7. Matthews K, Gallo L. Psychological perspectives on pathways linking socioeconomic status and physical health. Annu Rev Psychol. 2011;62:501-30. 
8. Adler N, Bush N, Pantell M. Rigor, vigor, and the study of health disparities. Proc Natl Acad Sci U S A. 2012;109:17154-9.

9. Konlaan B, Björby N, Bygren L, Weissglas G, Karlsson LG, Widmark M. Attendance at cultural events and physical exercise and health: a randomized controlled study. Public Health. 2000;114:316-9.

10. Johansson S, Konlaan B, Bygren L. Sustaining habits of attending cultural events and maintenance of health: a longitudinal study. Health Promot Int. 2001;16:229-34.

11. Khawaja M, Mowafi M. Cultural capital and self-rated health in low income women: evidence from the urban health study, Beirut, Lebanon. J Urban Health. 2006:83:444-58

12. Veenstra G. Social space, social class and Bourdieu: health inequalities in British Columbia, Canada. Health Place. 2007;13:14-31.

13. Abel T, Fuhr D, Bisegger C, Ackermann Rau S, European Kidscreen Group. Money is not enough: exploring the impact of social and cultural resources on youth health. Scand J Public Health. 2011;39:57-61.

14. Almedom A. Social capital and mental health: an interdisciplinary review of primary evidence. Soc Sci Med. 2005;61:943-64.

15. Islam M, Merlo J, Kawachi I, Lindström M, Gerdtham UG. Social capital and health: does egalitarianism matter? A literature review. Int J Equity Health. 2008:5:3.

16. Uphoff E, Pickett $K$, Cabieses B, Small N, Wright J. A systematic review of the relationships between social capital and socioeconomic inequalities in health: a contribution to understanding the psychosocial pathway of health inequalities. Int J Equity Health. 2013;12:54

17. Abel T. Cultural capital and social inequality in health. J Epidemiol Community Health. 2008;62, e13.

18. Abel T, Frohlich K. Capitals and capabilities: linking structure and agency to reduce health inequalities. Soc Sci Med. 2012;74:236-44.

19. Veenstra G, Patterson A. Capital relations and health: mediating and moderating effects of cultural, economic, and social capitals on mortality in Alameda County, California. Int J Health Serv. 2012;42:277-91.

20. Frohlich K, Abel T. Environmental justice and health practices: understanding how health inequities arise at the local level. Sociol Health IIIn. 2014;36:199-212.

21. Mensah F, Hobcraft J. Childhood deprivation, health and development: associations with adult health in the 1958 and 1970 British prospective birth cohort studies. J Epidemiol Community Health. 2008;62:599-606.

22. Iversen A, Holsen I. Inequality in health, psychosocial resources and health behavior in early adolescence: the influence of different indicators of socioeconomic position. Child Indic Res. 2008;1:291-302.

23. Evans M, Kelley J, Sikora J, Treiman DJ. Family scholarly culture and educational success: books and schooling in 27 nations. Res Soc Stratif Mobil. 2010;28:171-97.

24. Westerlund H, Gustafsson P, Theorell T, Janlert U, Hammarström A. Parental academic involvement in adolescence, academic achievement over the life course and allostatic load in middle age: a prospective population-based cohort study. J Epidemiol Community Health. 2013;67:508-13.

25. Idler E, Benyamini Y. Self-rated health and mortality: a review of twentyseven community studies. J Health Soc Beh. 1997;38:21-37.

26. Burstrom B, Fredlund P. Self-rated health: Is it as good a predictor of subsequent mortality among adults in lower as well as in higher social classes? J Epidemiol Community Health. 2001;55:836-40.

27. Kestilä L, Koskinen S, Martelin T, Rahkonen O, Pensola T, Pirkola S, et al. Influence of parental education, childhood adversities, and current living conditions on daily smoking in early adulthood. Eur J Public Health. 2006;16:617-26.

28. Kvaavik E, Glymour M, Klepp K, Tell GS, Batty GD. Parental education as a predictor of offspring behavioural and physiological cardiovascular disease risk factors. Eur J Public Health. 2012;22:544-50.

29. Sonego M, Llácer A, Galán I, Simón F. The influence of parental education on child mental health in Spain. Qual Life Res. 2013;22:203-11.

30. Lundborg P, Nilsson A, Rooth D. Parental education and offspring outcomes: evidence from the Swedish compulsory School Reform. Am Econ J Appl Econ. 2014;6:253-87.

\section{Submit your next manuscript to BioMed Central and take full advantage of:}

- Convenient online submission

- Thorough peer review

- No space constraints or color figure charges

- Immediate publication on acceptance

- Inclusion in PubMed, CAS, Scopus and Google Scholar

- Research which is freely available for redistribution

Submit your manuscript at www.biomedcentral.com/submit 